\title{
Mobilization of hydrophobic contaminants from soils by enzymatic depolymerization of soil organic matter
}

\author{
Daniel Wicke, Thorsten Reemtsma* \\ Department of Water Quality Control, Technical University Berlin, Sekr KF 4, Strasse des 17, Juni 135, 10623 Berlin, Germany
}

\section{A R T I C L E I N F O}

\section{Article history:}

Received 5 August 2009

Received in revised form 1 December 2009

Accepted 4 December 2009

Available online $\mathrm{xxxx}$

\section{Keywords:}

Cellulase

Contaminants

Desorption

Enzymes

Mobilisation

Bacteria

\begin{abstract}
A B S T R A C T
The effect of hydrolytic exoenzymes on the release of hydrophobic organic contaminants (HOC) from two different surface soils was studied in laboratory batch experiments. Incubation of the soils with cellulase with an activity fivefold above the inherent soil activity enhanced the release of hydrophobic contaminants (polycyclic aromatic hydrocarbons (PAH), polychlorinated biphenyls (PCB) and hydroxylated PCB) by $40-200 \%$. Xylanase and invertase did not show measurable effects at comparable relative activity levels. This suggests that cellulose substructures are important for the retention of HOC in soil organic matter (SOM). Hydrolytic exoenzymes, and the microorganisms that release them, contribute to the mobilization of HOC from soil, by shifting the sorption equilibrium in the course of SOM transformation into dissolved organic matter or by facilitating HOC diffusion as a consequence of reduced rigidity of SOM. We conclude that not only biodegradation but also sorption and desorption of HOC in soil can be influenced by (micro-) biology and the factors that determine its activity.
\end{abstract}

(c) 2009 Published by Elsevier Ltd.
Q1

\section{Introduction}

Soil organic matter (SOM) has been shown to be the major sink for hydrophobic organic contaminants (HOC) in soils and sediments (Karickhoff et al., 1979; Means et al., 1980). Therefore, the organic carbon content of the respective soil and the $K_{\text {oc }}$-value of an organic contaminant are prime parameters to assess the extent of HOC sorption to a soil. However, SOM is a complex, heterogeneous mixture of molecules including biopolymers that underwent gradual decomposition through various degrees of diagenesis to form fulvic and humic acids and humin. These biopolymers include carbohydrates (e.g. cellulose, hemicellulose, extracellular polymeric substances - EPS), lipids, proteins, lignins and tannins. Although the composition of SOM can be very diverse, the macromolecular character and structure of the original biopolymers is preserved to some extent (Hayes et al., 1989).

Not all constituents of SOM contribute equally to the sorption of HOC. SOM quality influences both the thermodynamics of sorption, as visible from the respective $K_{\mathrm{oc}}$-value, and the kinetic of sorption, i.e. the rate at which equilibration between the water and the organic phase is attained. More aromatic and less polar SOM constituents exhibit higher sorption capacity (Wang et al., 2007), while viscous 'rubbery' states of SOM show relatively faster rates of sorption than more rigid 'glassy' states (Leboeuf and Weber, 2000).

\footnotetext{
* Corresponding author. Tel.: +49 3084123607.

E-mail addresses: thorsten.reemtsma@tu-berlin.de, thorsten.reemtsma@bfrbund.de (T. Reemtsma).
}

The amount and the quality of the particulate organic matter of a soil may be subject to change as SOM is continuously formed and degraded. SOM degradation leads to formation of carbon dioxide and of dissolved organic matter (DOM) (Reemtsma et al., 2003). In a conceptual model mineralization of SOM is preceded by hydrolytic cleavage of its polymers by exoenzymes of bacteria and fungi or by soil animals after ingestion. This decreases the molecular weight of the SOM molecules, increases their solubility, and makes them amenable to intra-cellular degradation (Schimmel and Weintraub, 2003). Indeed, a correlation between the degradation rate of SOM and the activity of extracellular enzymes in soil has been shown (Moorhead and Sinsabaugh, 2000).

Microbial activity in soils and, as a consequence, the mineralization of SOM and formation of DOM is influenced by external factors such as soil temperature, soil moisture content, and soil $\mathrm{pH}$ (Reemtsma et al., 2003). Correspondingly, it is being discussed whether increased DOM concentrations in rivers and streams are attributed to climate change or to changes in atmospheric deposition of inorganic ions (Evans et al., 2006; Hruska et al., 2009).

Because HOC sorption to a soil is closely associated with its SOM, the sorption capacity may be strongly affected by changes in SOM. Any factor that alters the amount and quality of SOM could also influence a soil's function as a sink for HOC. In soil column experiments enhanced mineralization of SOM (as detected by $\mathrm{CO}_{2}$ formation and DOM percolation out of the columns) has been shown to be accompanied by increased export of organic contaminants determined as adsorbable organic compounds (AOX, TOX) (Reemtsma et al., 2003). The study system, however, had been

0045-6535/\$ - see front matter (c) 2009 Published by Elsevier Ltd. doi:10.1016/j.chemosphere.2009.12.009 
too complex to prove a causal interrelationship between SOM mineralization and $\mathrm{HOC}$ release.

To further elucidate the potential link between (micro-) biological activity in soil and the release of organic contaminants, a less complex system than the one used by Reemtsma et al. (2003) was chosen for this study. Hydrolytic enzymes were added to soil samples, and the amount of PAH and PCB released during incubation with these enzymes was determined. By this approach the effects of three hydrolytic enzymes on the release of aged HOC in soil could be determined.

This study focuses on enzymes hydrolysing polysaccharides, as these are important constituents of SOM. It was assumed that partial lysis of glycosidic linkages in SOM by suitable hydrolytic enzymes transforms SOM into DOM, thus decreasing the amount of SOM. This would shift the partitioning equilibrium of HOC sorbed to SOM towards the dissolved phase (thermodynamic effect). Moreover, partial lysis of SOM could loosen its three-dimensional structure and reduce the rigidity of the organic phase, thus facilitating diffusive transport of HOC to the soil boundary layer and accelerating its transfer into the aqueous phase (kinetic effect). A decreasing viscosity upon treatment by hydrolytic enzymes has been observed for fulvic acids (Majumdar and Rao, 1978). Both the thermodynamic and the kinetic effect would support the transfer of sorbed HOC into the dissolved phase and would render them more mobile.

Previous studies investigating the influence of microorganisms on the fate of HOC in soil have often focussed on HOC transformation and degradation. This study highlights that (micro-) biology may influence partitioning of HOC in soil systems, and that factors that stimulate the activity of soil biology may also stimulate HOC release from soil.

\section{Materials and methods}

\subsection{Soil samples}

Soil samples of two different sites were taken (a) from a public park (Tiergarten) in the centre of Berlin, Germany and (b) a wastewater infiltration site at the northern border of the city of Berlin (Buch) which had been in operation for more than 100 years until 1985. During that time untreated municipal wastewater with large amounts of particulate matter had been infiltrated on this site resulting in accumulation of HOC in the soil surface layer (Reemtsma et al., 1997). Therefore, this soil contained appreciable concentrations of PCB $\left(200-1500 \mu \mathrm{g} \mathrm{kg}_{\lambda}^{-1}\right.$ for tri to tetrachlorinated biphenyls) and even higher concentrations of $\mathrm{PAH}$ (1.1$2.2 \mathrm{mg} \mathrm{kg}_{\wedge}^{-1}$ for 4- and 5-ring PAH).

Both sampling sites consist of sandy soils with the following characteristics: Buch: $95 \%$ sand, $4.7 \%$ silt, $0.3 \%$ clay, $15 \%$ water content (field moist sample oven-dried at $105^{\circ} \mathrm{C}$ for $24 \mathrm{~h}$ ), pH (aqueous extract) of 5.3 and an organic matter content (as determined by loss of ignition) of 5.3\%; Tiergarten: $85 \%$ sand, $10.5 \%$ silt, $4.5 \%$ clay, $16 \%$ water content, $\mathrm{pH}$ of 5.7 and a organic matter content of $7.5 \%$.

Two sets of samples were taken: in April 2004 from the wastewater infiltration site only (comparison of different enzymes), and in April 2005 from the wastewater infiltration site and the public park (comparison of cellulase addition in two different soils). Soil samples were taken from the humous upper layer $(10-20 \mathrm{~cm})$, sieved $(4 \mathrm{~mm})$ to remove roots and stones, and stored refrigerated in darkness until incubation experiments were conducted.

\subsection{Chemicals and reagents}

Enzymes (xylanase $\geqslant 2500 \mathrm{U} \mathrm{g}^{-1}$, invertase $\geqslant 175 \mathrm{U} \mathrm{mg}^{-1}$ and cellulase $\geqslant 1000 \mathrm{Ug}^{-\hat{\uparrow}}$ ) as well $\hat{\text { as }}$ substrates (xylan from oat spelts, carboxymethylcellulose sodium salt, sucrose and glucose) were all purchased from Sigma. Substrate solutions were prepared as follows: xylan solution: $1.2 \mathrm{~g}$ of xylan was added to $100 \mathrm{~mL}$ of water and stirred for $2 \mathrm{~h}$ at $45^{\circ} \mathrm{C}$; sucrose solution: $1.2 \mathrm{~g}$ of sucrose was added to $100 \mathrm{~mL}$ of water; cellulose solution: $0.7 \mathrm{~g}$ of $\mathrm{CM}$-cellulose sodium salt was added to $100 \mathrm{~mL}$ of water and stirred for $2 \mathrm{~h}$ at $45^{\circ} \mathrm{C}$.

PAH and PCB standards were purchased from Dr. Ehrenstorfer (Augsburg, Germany), hydroxylated PCB standards were available from Campro Scientific (Berlin, Germany). Only high purity solvents (of HPLC or residue analysis grade) were used.

A solution of deuterated PAH and ${ }^{13} \mathrm{C}$-labeled PCB standards was prepared in propanol at a concentration of $5 \mathrm{mg} \mathrm{L}_{A}^{-1}$ for each compound and included the following substances: phenanthrene$\mathrm{d} 10$, fluoranthene-d10, benzo[a]anthracene-d12, benzo[a]fluoranthene-d12, 3,4,4' -trichlorobiphenyl- ${ }^{13} \mathrm{C}, 2,3^{\prime}, 4^{\prime}, 5$-tetrachlorobiphenyl- ${ }^{13} \mathrm{C}$ and $2,3^{\prime}, 4,4^{\prime}, 5$-pentachlorobiphenyl- ${ }^{13} \mathrm{C}$ (all from LGC Promochem, Wesel, Germany).

\subsection{Determination of enzyme activity in soils}

The inherent enzyme activity of the soils was determined as adapted from Schinner and von Mersi (1990) by adding $15 \mathrm{~mL}$ of the respective substrate solution (xylan solution for xylanase activity, sucrose solution for invertase activity and CM-cellulose solution for cellulase activity) to $5 \mathrm{~g}$ of soil and $15 \mathrm{~mL}$ deionised water. After incubation $\left(24 \mathrm{~h}\right.$ at $50^{\circ} \mathrm{C}$ on a water bath rotary shaker at $120 \mathrm{rpm}$ ), all mixtures were deactivated ( $5 \mathrm{~min}$ in boiling water bath), and supernatants were filtered using a paper filter (Sartorius, Goettingen, Germany). The filtrates were diluted (for invertase determination: $1: 10$, for xylanase determination: $1: 2$, for cellulase determination: undiluted) before using $500 \mu \mathrm{L}$ of the resulting solution for glucose determination. This colorimetric measurement was done applying the Somogyi-Nelson method according to Wood and Bhat (1988). The results were corrected for soil water content to relate the enzymatic activity to the soils dry weight.

\subsection{Batch experiments}

Two series of batch experiments were performed. In a first batch, one soil (wastewater infiltration site) was incubated in parallel with one of the three different polysaccharide-degrading enzymes cellulase, invertase and xylanase. In a second batch, the effect of cellulase, which proved to be the most effective enzyme in terms of PAH and PCB release in the first batch, was compared in two different soils (wastewater infiltration site and public park). In both series the amount of the respective enzyme added to the soil solutions was adjusted to 500-fold of the inherent enzyme activity based on the measurements described in 2.3 (added amounts to $50 \mathrm{~g}$ soil: xylanase: $8.6 \mathrm{mg}$, invertase: $2.3 \mathrm{mg}$ and cellulase: $282 \mathrm{mg}$ to soil of wastewater infiltration site and $606 \mathrm{mg}$ to park soil). A schematic view of enzymatic incubation and sample analysis is shown in Fig. 1a. In principle, $130 \mathrm{~mL}$ of deionised water was added to $50 \mathrm{~g}$ of soil in a glass bottle together with one of the following variants: $2 \mathrm{~mL}$ enzyme solution, $2 \mathrm{~mL}$ deactivated (30 min at $130{ }^{\circ} \mathrm{C}$ autoclaved) enzyme solution, or $2 \mathrm{~mL}$ deionised water. All bottles of each series were incubated in parallel at $50{ }^{\circ} \mathrm{C}$ on a water bath rotary shaker $(120 \mathrm{rpm})$ in the dark for $24 \mathrm{~h}$. The concentrations of PAH and PCB that were released during incubation of the soil samples were determined in the supernatants at the end of the incubation experiment after $24 \mathrm{~h}$.

\subsubsection{Enzyme activity during incubation}

To determine the enzyme activity in the supernatant during the incubation, an aliquot of the supernatant $(200 \mu \mathrm{L}$ for xylanase, 
A
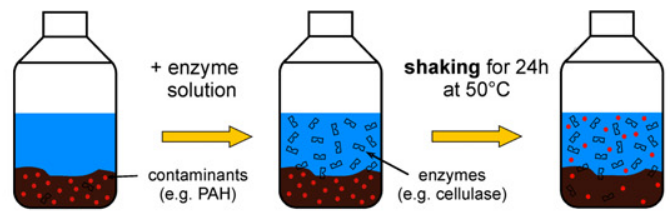

soil sample $(50 \mathrm{~g})$

+ deionized water $(130 \mathrm{ml})$

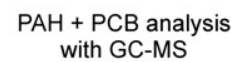
with GC-MS

B
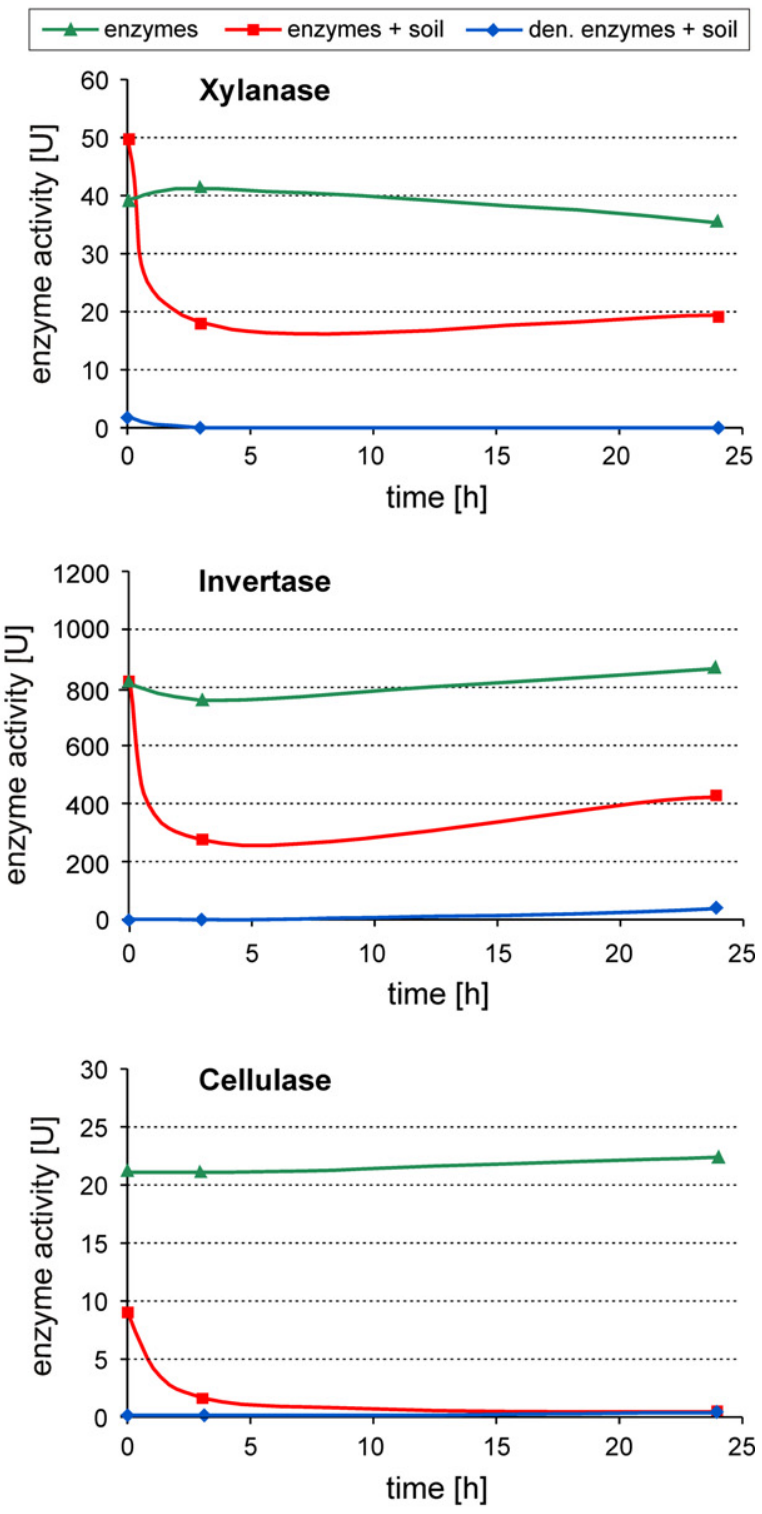

Fig. 1. (A) Experimental workflow of the soil incubation experiments with hydrolytic enzymes; (B) time course of the activity of xylanase, invertase and cellulase in the supernatant of the respective incubation experiment ( $1 \mathrm{U}=1 \mu$ mol $_{\text {glucose }} \mathrm{h}^{-1}$ ).

$100 \mu \mathrm{L}$ for invertase and $500 \mu \mathrm{L}$ for cellulase activity) was taken at different times ( $t=0 \mathrm{~h}, 3 \mathrm{~h}, 24 \mathrm{~h}$ ) and filled up with water to a volume of $5 \mathrm{~mL}$. Then, the diluted sample was spiked with $5 \mathrm{~mL}$ of the respective substrate solution and incubated at $50{ }^{\circ} \mathrm{C}$ for $30 \mathrm{~min}$. The glucose concentration (resulting from enzymatic reactions) was measured using the Somogyi-Nelson method (see above). To assess the stability of the enzymes in a pure aqueous solution, a control experiment without soil (deionised water + enzymes) was incubated in parallel.

\subsubsection{Additional measurements}

Dissolved organic carbon (DOC) concentration was determined at the beginning and at the end of the incubation experiment after filtration of the supernatant over $0.45 \mu \mathrm{m}$ filters using a TOC analyzer (high TOC, Elementar, Hanau, Germany) with catalytic high temperature combustion.

\subsection{Determination of $P A H, P C B$ and $O H-P C B$}

\subsubsection{Supernatant}

After incubation, solutions were decanted into glass centrifuge tubes and centrifuged for $15 \mathrm{~min}$ at $1600 \mathrm{~g}$. The complete supernatants were transferred into a methanol-washed glass bottle, acidified to $\mathrm{pH} 3$, and spiked with four deuterated PAH and three ${ }^{13} \mathrm{C}$ labelled PCB $(10 \mu \mathrm{L}$ of the labelled standard solution - see Section 2.2) as internal standards to correct for losses during the extraction and clean-up procedure. Solid phase extraction (SPE) of the supernatant was performed by the AutoTrace workstation (Zymark, Hopkinton, USA) using $200 \mathrm{mg}$ Oasis HLB extraction cartridges (Waters, Eschborn, Germany) and an acetone-toluene mixture $(9: 1 ; v: v)$ as eluent. The automated procedure included conditioning of the cartridges (with $5.5 \mathrm{~mL}$ eluent, $5.5 \mathrm{~mL}$ methanol and $5.5 \mathrm{~mL}$ ultrapure water), sample passage at a flow rate of $4 \mathrm{~mL} \mathrm{~min}^{-1}$, drying of the cartridges ( $30 \mathrm{~min}$ with $\mathrm{N}_{2}$ ), and 5 elution steps (total eluate volume: $8 \mathrm{~mL}$ ). After SPE, one drop of octanol was added to each eluate, eluates were concentrated to a volume of approximately $0.5 \mathrm{~mL}$ using a SpeedVac concentrator (Savant, Thermo) and transferred to a GC-MS vial. For derivatisation (for detection of hydroxylated PCB metabolites) solvents were evaporated under a gentle stream of nitrogen (except the octanol drop), and $200 \mu \mathrm{L}$ of diazomethane solution was added to each vial. After a reaction time of $60 \mathrm{~min}$ the vials were opened, excessive diazomethane was evaporated, and $190 \mu \mathrm{L}$ of a hexane/toluenemixture $(6: 4 ; \mathrm{v}: \mathrm{v})$ was added together with $10 \mu \mathrm{L}$ of triphenylmethane $\left(10 \mathrm{mg} \mathrm{L}_{\wedge}^{-1}\right)$ as injection spike prior to $\mathrm{GC}_{\Lambda} \mathrm{C}-\mathrm{MS}$ analysis.

\subsubsection{Soil samples before incubation}

Concentration of PAH and PCB in soil were determined after Soxhlet extraction with ethyl acetate and silica gel cleanup. Blanks (samples without soil) proved that no contamination of the target analytes were introduced during the extraction processes.

\subsubsection{GC-MS analysis}

Separation of $\mathrm{PAH}$ and $\mathrm{PCB}$ was performed using a Fisons GC8000 gas chromatograph with splitless injection (injection volume: $1 \mu \mathrm{L}$ ). A fused silica capillary column (Zebron ZB5-MS, $30 \mathrm{~m} \times 0.25 \mathrm{~mm} \times 0.25 \mu \mathrm{m}$ film thickness, Phenomenex Inc., USA) was used with helium as carrier gas. Compounds were identified and quantified using a Fisons MD800 quadrupole mass spectrometer in the selected ion recording (SIR) mode with en electron impact ionization of $70 \mathrm{eV}$. Temperature for the injector and interface was set to $250^{\circ} \mathrm{C}$. The oven temperature program started at $90^{\circ} \mathrm{C}$, held for $2 \mathrm{~min}$, increased to $180^{\circ} \mathrm{C}$ at $10^{\circ} \mathrm{C} \mathrm{m^{-1 }}$, increased to $280{ }^{\circ} \mathrm{C}$ at $8{ }^{\circ} \mathrm{C} \mathrm{min}^{-1}$, and held for $15 \mathrm{~min}$ (totâ run length $39 \mathrm{~min}$ ). An overview of the analytes is given in Table 1.

\subsubsection{Identification and quantification}

Identification of PAH compounds was based on the comparison of retention time data between samples and the standard solutions, whereas individual PCB peaks were identified by comparison of the corresponding mass spectrum with those in the National 
Table 1

Analytical parameters and physico-chemical properties of the analytes.

\begin{tabular}{|c|c|c|c|c|c|c|}
\hline$n^{\mathrm{a}}$ & Analyte name & $\mathrm{m} / \mathrm{z}$ & $\mathrm{RT}^{\mathrm{b}}(\mathrm{min})$ & ISTD $^{\mathrm{c}}$ & $\log K_{\text {ow }}{ }^{d}$ & Solubility $^{\mathrm{e}}\left(\mu \mathrm{g} \mathrm{L}^{-1}\right)$ \\
\hline \multicolumn{7}{|c|}{$P C B$} \\
\hline 7 & Trichlorobiphenyls (tri-CB) & 256 & $13.9-16.0$ & $3,4,4^{\prime}-$ Tri-CB- ${ }^{13} \mathrm{C}$ & 5.7 & $130-410$ \\
\hline 10 & Tetrachlorobiphenyls (tetra-CB) & 292 & $16.4-18.0$ & $2,3^{\prime}, 4^{\prime}, 5$-Tetra-CB- ${ }^{13} \mathrm{C}$ & 5.9 & $5-92$ \\
\hline 12 & Pentachlorobiphenyls (penta-CB) & 326 & $18.0-20.7$ & $2,3^{\prime}, 4,4^{\prime}, 5$-Penta-CB- ${ }^{13} \mathrm{C}$ & 6.4 & $1-21$ \\
\hline \multicolumn{7}{|c|}{ Hydroxy-PCB (OH-PCB) } \\
\hline 8 & Trichlorohydroxiybiphenyls ${ }_{\hat{\lambda}}(\mathrm{OH}-\mathrm{tri}-\mathrm{CB})$ & 286 & $17.7-19.1$ & $3,4,4^{\prime}-$ Tri-CB- ${ }^{13} \mathrm{C}$ & 5.1 & n.a. \\
\hline 8 & Tetrachlorohydroxybiphenyls (OH-tetra-CB) & 322 & $19.8-21.2$ & $2,3^{\prime}, 4^{\prime}, 5$-tetra-CB- ${ }^{13} \mathrm{C}$ & 5.5 & n.a. \\
\hline \multicolumn{7}{|c|}{ 3-ring $P A H$} \\
\hline \multirow[t]{3}{*}{3} & Fluorene & 165 & 12.8 & Phenanthrene-d10 & 4.2 & 1850 \\
\hline & Phenanthrene & 178 & 15.4 & Phenanthrene-d10 & 4.6 & 1240 \\
\hline & Anthracene & 178 & 15.5 & Phenanthrene-d10 & 4.5 & 64 \\
\hline \multicolumn{7}{|c|}{ 4-ring $P A H$} \\
\hline \multirow[t]{4}{*}{4} & Fluoranthene & 202 & 19.0 & Fluoranthene-d10 & 5.2 & 245 \\
\hline & Pyrene & 202 & 19.7 & Fluoranthene-d10 & 5.2 & 132 \\
\hline & Benzo[a]anthracene & 228 & 23.5 & Benzo[a]anthracene-d12 & 5.6 & 14 \\
\hline & Chrysene & 228 & 23.6 & Benzo[a]anthracene-d12 & 5.9 & 1.8 \\
\hline \multicolumn{7}{|c|}{ 5-ring $P A H$} \\
\hline \multirow[t]{4}{*}{4} & Benzo[b]fluoranthene & 252 & 27.4 & Benzo[a]fluoranthene-d12 & 6.6 & 1.0 \\
\hline & Benzo[k]-fluoranthene & 252 & 27.5 & Benzo[a]fluoranthene-d12 & 6.6 & 1.0 \\
\hline & Benzo[a]pyrene & 252 & 28.9 & Benzo[a]fluoranthene-d12 & 6.6 & 1.6 \\
\hline & Dibenzo[a,h]anthracene & 278 & 36.2 & Benzo[a]fluoranthene-d12 & 7.2 & 0.7 \\
\hline
\end{tabular}

\footnotetext{
a Number of analytes per group.

b Retention time in the GC-MS analysis.

c Internal standard used for quantification.

d Octanol-water partition coefficients. Values for PAH and PCB (PCB 28, 52 and 101) from Krauss and Wilcke (2001), OH-PCB: calculated values (SciFinder, American Chemical Society).

e Solubility in water. Data for PCB: from Lang (1992), for PAH from Wild and Jones (1995).
}

Institute of Standards and Technology (NIST) mass spectral database.

For quantification, each sample set was supplemented with a standard series consisting of 5 concentrations $(5,10,50,100$, and $250 \mu \mathrm{g} \mathrm{L}^{-1}$ ). Compounds were quantified after integration of the selected ion chromatograms using the seven internal standards (Table 1). For quantitative determination of PCB and hydroxylated $P C B$, each group of PCB (e.g. trichlorobiphenyls (tri-CB)) was represented by one reference compound (e.g. 2,4,4'-tri-CB), whose calibration curve was applied to all identified compounds of the respective group, whereas for $\mathrm{PAH}$ a calibration curve was measured for each investigated compound. The coefficient of determination $\left(R^{2}\right)$ of all calibration curves was $>0.99$.

With each set of samples, a solvent blank, a standard mixture, and a procedural blank were run in sequence to check for contamination, peak identification and quantification. Recovery from spiked solutions (concentration level $200 \mathrm{ng} \mathrm{L}^{-1}$ ) was determined in duplicate for $\mathrm{PAH}, \mathrm{PCB}$ and $\mathrm{OH}-\mathrm{PCB}$ and ranged from $78.7 \pm 3.2 \%$ for penta-CB to $99.8 \pm 3.7 \%$ for $\mathrm{OH}$-tri-CB. The average recovery was $87 \pm 7 \%(n=34)$ for the duplicate analysis of 17 analytes.

\section{Results and discussion}

\subsection{Enzyme activity during soil incubation}

The activity of cellulase, xylanase, and invertase in the soil solutions (supernatant) was monitored during the incubation experiments (Fig. 1b). Results of the batches with enzyme in pure water demonstrate the stability of all enzymes in water over the whole incubation period ( $24 \mathrm{~h}$ ). In the batches containing soil, however, the activity of all enzymes in the supernatant decreased strongly but to different extent. While the activity of xylanase and invertase was reduced to about half of the initial activity within the first $3 \mathrm{~h}$ and then remained nearly constant until the end of the experiment, the activity decrease of cellulase was more pronounced
(Fig. 1b). Already the first sample of the supernatant (taken directly after addition of the enzyme solution) showed a reduction of cellulase activity to less than half of the corresponding value without soil. After $24 \mathrm{~h}$ no cellulase activity could be measured in the supernatant (Fig. 1b).

The decrease of enzyme activity in the supernatant (Fig. 1b) is likely due to precipitation reactions, interference with clay minerals, degradation by proteolytic microorganisms, and attachment of enzyme molecules to soil particles (Burns, 1977, 1982; Quiquampoix et al., 1993; Huang et al., 2005). Enzyme activity may also be reduced in aqueous solution due to interaction with humic acids (Ladd and Butler, 1971).

In the soil phase, however, enzyme activity remained elevated in all experiments. It was 5-7 times higher for all three enzymes at the end of the incubation period $(24 \mathrm{~h})$ as compared to the inherent enzyme activities determined before the experiment (Table 2). It has been shown previously that enzymes may retain part of their activity after attachment to soil particles (Burns, 1977,1982) and in colloidal matter (Lahdesmaki and Piispanen, 1992), where they may be stabilized against proteolytic attack (Sarkar et al., 1989). It is likely that these processes also occurred during the incubation experiments. Therefore, it is not surprising that even cellulase activity remained elevated in the soil, although activity in the aqueous solution declined to zero.

\subsection{Effect of various enzymes on contaminant release in one soil}

The importance of cellulase, xylanase, and invertase as hydrolytic enzymes in soils has often been demonstrated (e.g. Schinner and von Mersi, 1990; Deng and Tabatabai, 1994; Stemmer et al., 1999). Other hydrolytic enzymes of importance in soil are urease, glucosidase, galactosidase and proteases (Burns, 1977, 1982).

To determine whether the enhanced enzyme activity of cellulase, xylanase, and invertase in the soil influences the release of HOC, three parallel incubations were performed with each of the three enzymes: (a) soil with heat-deactivated enzyme, (b) soil with 
Table 2

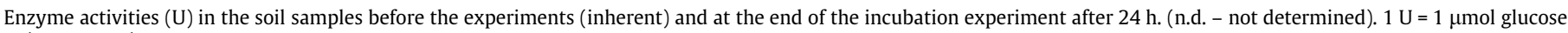
$\mathrm{g}^{-1}$ soil $24 \mathrm{~h}^{-1}$

\begin{tabular}{|c|c|c|c|c|c|c|}
\hline & \multicolumn{2}{|c|}{ Cellulase (U) } & \multicolumn{2}{|c|}{ Xylanase (U) } & \multicolumn{2}{|c|}{ Invertase $(\mathrm{U})$} \\
\hline & Inherent $^{\mathrm{a}}$ & End $^{\mathrm{b}}$ & Inherent & End & Inherent & End \\
\hline Wastewater infiltration site & $0.27 \pm 0.08$ & 1.8 & $1.25 \pm 0.14$ & 9.2 & $22.7 \pm 3.2$ & 138 \\
\hline Public park & $0.57 \pm 0.15$ & 2.7 & n.d. & n.d. & n.d. & n.d. \\
\hline
\end{tabular}

a Inherent: enzyme activity in the soil sample before enzyme addition; mean $\pm S(x), n=3$.

b Enzyme activity in the soil after incubation with the respective enzyme for $24 \mathrm{~h}$.

active enzyme, and (c) soil without any addition of enzyme as the control (soil and water only).

The amount of HOC released due to the action of the respective enzyme was determined from the difference between the incubation with the active and the deactivated enzyme (comparison of (a) and (b)). The released amounts of HOC are summarized for compound groups in Fig. 2. Without any enzyme added (c) the released amounts ranged from 2 to $10 \mathrm{ng} \mathrm{g}^{-1}$ soil for the PCB groups (Fig. 2a), from 0.3 to $1.3 \mathrm{ng} \mathrm{g}^{-1}$ for the hydroxylated PCB (Fig. 2b) and from 0.06 to $0.23 \mathrm{ng} \mathrm{g}_{\wedge}^{-1}$ for the PAH groups (Fig. 2c). In most cases the pure water (c) and the deactivated enzyme (b) incubation showed comparable HOC concentrations in the supernatant. This indicates that the inactive enzyme, despite of its high concentration (resulting in DOC-concentrations in the supernatant of up to
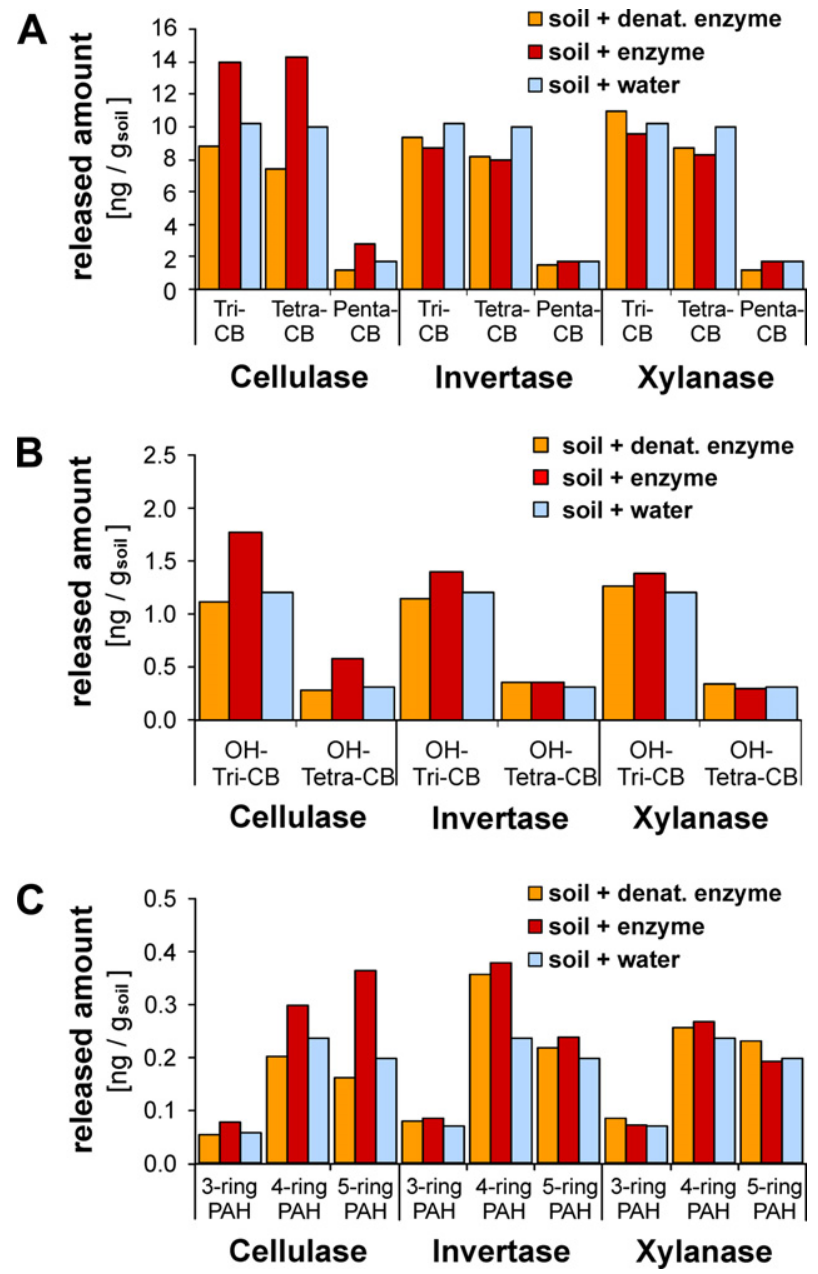

Fig. 2. Influence of cellulase, xylanase and invertase on the release of $(A) P C B,(B)$ $\mathrm{OH}-\mathrm{PCB}$ and $(\mathrm{C}) \mathrm{PAH}$ from a soil sample of the wastewater infiltration site.
$800 \mathrm{mg} \mathrm{L}_{\wedge}^{-1}$ in the case of cellulase addition), did not influence the release of HOC.

Of the active enzymes only cellulase induced a measurable release of the investigated contaminants $\mathrm{PCB}$, hydroxylated $\mathrm{PCB}$ and PAH (Fig. 2). This increase ranged from $43 \%$ for the less hydrophobic 3-ring PAH to $100 \%$ for the more hydrophobic penta-CB and $125 \%$ for 5 -ring PAH (Table 3 ). The addition of xylanase and invertase only slightly increased the concentration of $\mathrm{OH}-\mathrm{tri}-\mathrm{CB}$ in the supernatant (Fig. 2b) and did not influence the other contaminant groups (tri- $\mathrm{CB}$, tetra- $\mathrm{CB}$, penta- $\mathrm{CB}, \mathrm{OH}$-tetra- $\mathrm{CB}$, 3-ring- $\mathrm{PAH}, 4$ ring-PAH, and 5-ring-PAH) (Fig. 2a-c).

This difference between cellulase on one side and xylanase and invertase on the other side is explainable by the different substrates that these enzymes are able to hydrolyze: (a) cellulase catalyzes the hydrolysis of $\beta-1,4$-glycosidic linkages as in cellulose, the most frequently occurring organic compound in the biosphere, (b) xylanase decomposes $\beta$-1,4-glycosidic linkages in xylan, the most common constituent of hemicellulose and (c) invertase breaks down $\alpha$-1,2-glycosidic linkages in the disaccharide sucrose, which occurs only at later stages of biopolymer degradation.

It has been shown that cellulose as such is a comparatively weak sorbent for HOC (Leboeuf and Weber, 2000), with $K_{\mathrm{oc}}$-values for PAH being about 2 orders of magnitude lower compared to SOM (Jonker 2008). This weak sorption capacity of cellulose is due to its high polarity and low aromaticity (Wang et al., 2007). Thus, it is unlikely that the stronger releasing effects of cellulase would be due to the favourable sorption properties of cellulose in SOM. Rather it may indicate that cellulose or ageing products of cellulose that exhibit $\beta$-1,4-glycosidic linkages are a more important constituent of SOM as compared to hemicellulose structures with $\alpha-1,2$-glycosidic linkages. Indeed, cellulose together with lignin constituents have been shown to be comparatively stable plant constituents during senescence (Lahdesmaki and Piispanen, 1988). This is consistent with the observation that cellulase, besides alpha-amylase, was the most effective enzyme to release glucose from aquatic fulvic acid (Bertino et al., 1987).

\subsection{Repeatability and mode of action}

The second incubation experiment (using cellulase only) also included another sample of the same wastewater infiltration site. To assess the repeatability of the elevated HOC release caused by cellulase in the first experiment, these results were compared to the releasing effect of cellulase in the second experiment (Table 3 ). This second experiment confirms the findings of the first incubation regarding the effect of cellulase, with an average relative difference of the releasing effect between the two experiments of $13.7 \pm 9.9 \%$. Whereas most contaminant groups show very similar results for both soils (Table 3), the difference of three groups was more pronounced: for tri-CB (196\% instead of $159 \%)$ and OH-triCB (194\% instead of 158\%) the releasing effect was stronger, whereas for 5-ring PAH it was less pronounced (157\% instead of $225 \%$ ). These differences for two samples from the same site reflect the well known heterogeneity in soil systems. Two samples, even 
Table 3

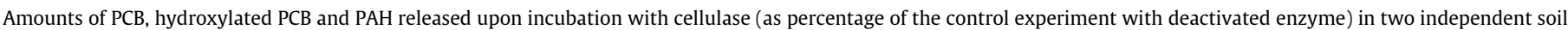
samples of the wastewater infiltration site.

\begin{tabular}{llc}
\hline & \% of control & Wastewater infiltration site (experiment 2) \\
\cline { 2 - 3 } & Wastewater infiltration site (experiment 1) & 196 \\
\hline$P C B$ & 159 & 192 \\
Tri-CB & 192 & 186 \\
Tetra-CB & 200 & 194 \\
Penta-CB & & 230 \\
OH-PCB & 158 & 157 \\
OH-tri-CB & 200 & 141 \\
OH-tetra-CB & & 157 \\
PAH & 143 & 150 \\
3-ring PAH & 225 & \\
4-ring PAH & & \\
5-ring PAH & & \\
\hline
\end{tabular}

when taken in close proximity to each other, are hardly ever entirely identical neither in bulk parameters nor in the contaminant content (Table 4). Besides these differences in soil quality the relative releasing effect of cellulase incubation was largely comparable.

There are at least two ways by which increased cellulase activity and the hydrolysis of cellulose substructures may influence the release of HOC from soil. (i) The decrease in SOM molecular weight increases water solubility and leads to a transformation of SOM into DOM. This reduces sorbent mass and, for thermodynamic reasons, results in the release of HOC to follow this trend. (ii) Partial lysis of SOM may loosen its three-dimensional structure and reduce the rigidity and the viscosity of the organic phase. This would facilitate diffusive transport of HOC to the soil boundary layer and accelerate its transition into the aqueous phase. Experimental evidence for a decreasing viscosity due to the action of hydrolytic enzymes has been provided for dissolved fulvic acids (Majumdar and Rao, 1978).

However, from these batch experiments with a contact time of $24 \mathrm{~h}$ between the soil and the water phase one cannot decide on the mechanism that has supported HOC release. Release experiments under kinetic control, e.g. in the flow through mode with high flow rates (Wicke et al., 2007, 2008), would be required to elucidate whether thermodynamic or kinetic effects or both supported HOC release upon SOM lysis.

\subsection{Comparison of cellulase influence in two different soils}

To verify whether the mobilizing effect of cellulase was specific for the highly contaminated wastewater infiltration site the second incubation experiment (with cellulase only) compared two different soils and included a soil of a public park with a different texture (lower particle size), a higher organic carbon content (7.5\%), and a different history of use and contamination (Table 4). Contrary to the wastewater infiltration site (Reemtsma et al., 1997) the public park did not receive raw sewage with a high particle load. Thus, its PCB concentration is about two orders of magnitude lower (4$10 \mu \mathrm{g} \mathrm{kg}_{\wedge}^{-1}$ ) than at the wastewater infiltration site (Table 4). The PAH concentration, however, is only about a factor of 3-4 lower (150-750 $\mu \mathrm{g} \mathrm{kg}_{\wedge}^{-1}$ per group; Table 4), which likely reflects the relevance of atmospheric inputs of $\mathrm{PAH}$ from burning of coal and from traffic at this urban site.

The temporal trend of the cellulase activity in the soil solutions during incubation was comparable to the first set of experiments, with a sharp decline within the first few hours (data not shown). However, after incubation the activity of cellulase in the soil itself again remained elevated with five times the initial, inherent activity (Table 2).

Results for the release of HOC in the two different soils (from public park and former wastewater infiltration site) upon parallel incubation by cellulase are compared in Fig. 3. The concentration of PCB and PAH in solution increased due to the action of cellulase for both soils. The increase varied between $40 \%$ (4-ring PAH in soil of the wastewater infiltration site) and 200\% (penta-CB in public park soil).

The absolute amount of PCB, however, that was released during incubation differed strongly between the two soils (Fig. 3). While 1.5- $4 \mathrm{ng} \mathrm{g}^{-1}$ of tri-, tetra- and penta-CB were released from the infiltration site, only $0.15-0.18 \mathrm{ng} \mathrm{g}_{\widehat{\wedge}}^{-1}$ were released from the park soil. This was due to the much higher PCB concentration in the soil of the wastewater infiltration site (Table 4).

The amounts of HOC released during the incubation experiments can also be compared to the initial concentrations in the soils (Table 4). A comparison of the contaminant classes shows a higher availability of the PCB as compared to the PAH in both soils. This indicates that PAH with their large aromatic system and, thus,

Table 4

Composition of the soil samples, content of PCB and $\mathrm{PAH}_{\Lambda}$ and portion released during incubation with cellulase.

\begin{tabular}{|c|c|c|c|c|c|}
\hline & Wastewater infiltration site, 1 st sample & Wastewater infiltration site, 2nd sample & \% Released & Public park & \% Released \\
\hline Sand (\%) & 95 & n.d. & & 85 & \\
\hline Silt (\%) & 4.7 & n.d. & & 10.5 & \\
\hline Clay $(\%)$ & 0.3 & n.d. & & 4.5 & \\
\hline Organic matter (\%) & 5.3 & 6.1 & & 7.5 & \\
\hline \multicolumn{6}{|l|}{$P C B^{\mathrm{a}}$} \\
\hline Tri-CB $\left(\mu \mathrm{g} \mathrm{kg}^{-1}\right)$ & 385 & 196 & 0.81 & 4 & 3.61 \\
\hline Tetra-CB $\left(\mu \mathrm{g} \mathrm{kg}^{-1}\right)$ & 1389 & 744 & 0.54 & 7 & 2.50 \\
\hline Penta-CB $\left(\mu \mathrm{g} \mathrm{kg}^{-1}\right)$ & 1503 & 368 & 0.44 & 10 & 1.60 \\
\hline \multicolumn{6}{|l|}{ PAH } \\
\hline 3-ring $\mathrm{PAH}\left(\mu \mathrm{g} \mathrm{kg}^{-1}\right)$ & 341 & 646 & 0.036 & 153 & 0.186 \\
\hline 4-ring $\mathrm{PAH}\left(\mu \mathrm{g} \mathrm{kg}^{-1}\right)$ & 2194 & 1648 & 0.019 & 745 & 0.092 \\
\hline 5-ring $\mathrm{PAH}\left(\mu \mathrm{g} \mathrm{kg}^{-1}\right)$ & 1124 & 1633 & 0.014 & 432 & 0.078 \\
\hline
\end{tabular}

a Hydroxylated PCB could not be determined in the soil extracts due to the clean-up procedure. 
A

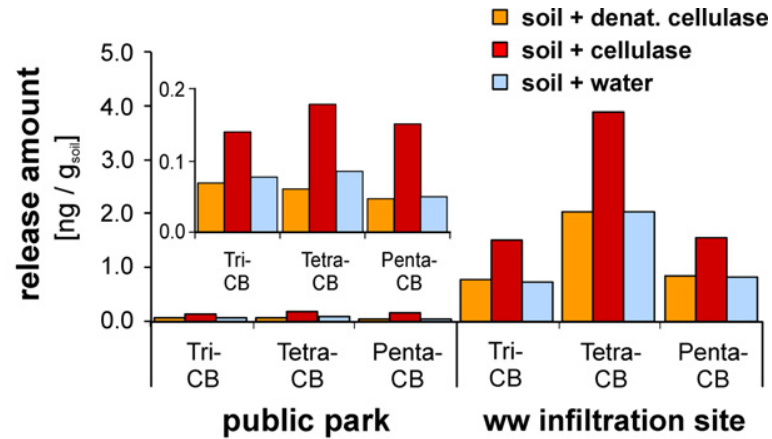

B

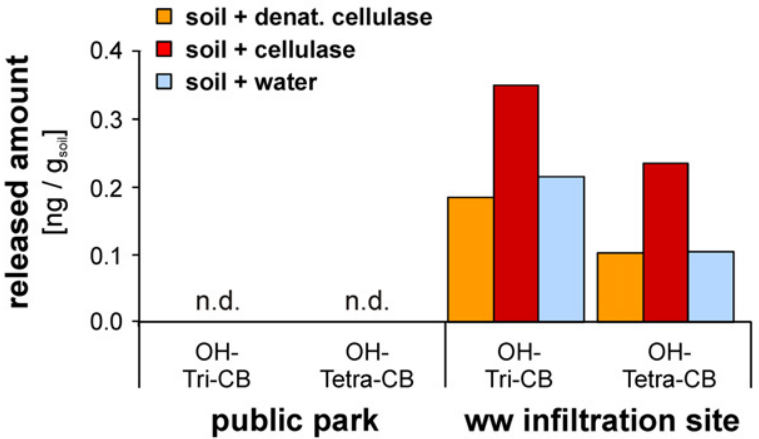

C

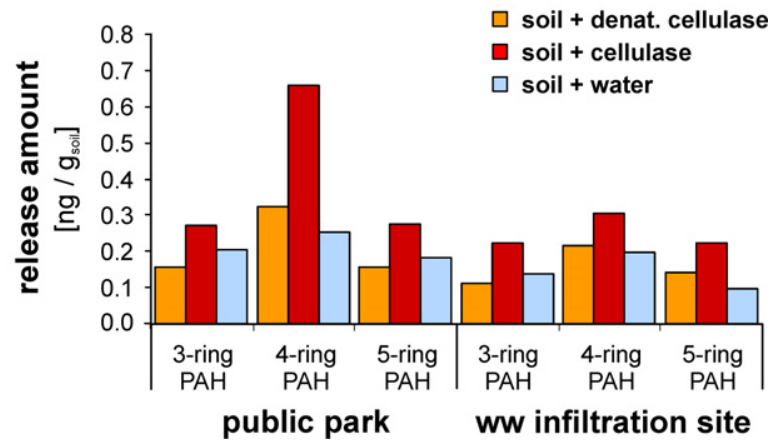

Fig. 3. Influence of cellulase on the release of (A) PCB, (B) OH-PCB and (C) PAH from two different soils (public park and wastewater infiltration site).

stronger interaction by the $\pi$-electrons system are more tightly bound to SOM than PCB. This is not adequately reflected in their $K_{\text {ow}}$-values (Table 1 ). Within each contaminant group, however, availability decreases with increasing $K_{\text {ow }}$-values from tri-CB to penta-CB and from 3-ring PAH to the five-ring PAH.

A comparison of the two soils (Table 4) shows that the availability (released fraction) of both, $\mathrm{PAH}$ and $\mathrm{PCB}$, from the public park soil was by a factor of 4-5 higher than from the wastewater infiltration site. Considering the finer texture of the park soil and its higher organic carbon content (Table 4) this is remarkable because both properties are usually associated with a higher sorption potential. An explanation may be found in the different history rather than in the present physico-chemical properties of the two soils. Large amounts of water have passed through the soil of the infiltration site for almost one century and it may, thus, be conceivable that well available HOC have been washed out, and only tightly bound fractions of HOC remained.

Despite these differences between the two soils the enzyme incubation experiments indicate that HOC release by hydrolytic attack of cellulase on SOM is not a specific phenomenon for one soil, but likely to occur in many different soils. Thus, (micro-) biological activity in soils, from which the exoenzymes originate, influences the sorption properties of a soil. Increasing microbial activity could weaken a soils function as a sink for HOC.
This finding is in contrast to the proposal of using microorganisms to immobilize contaminants in soils through formation of bound residues (Berry and Boyd, 1985). That concept was based on the idea of oxidative coupling of HOC to soil constituents (Weber and Huang, 2003) for which the use of exoenzymes such as peroxidases or polyphenol oxidases has been proposed (Bollag, 1992). Not all contaminants are, however, amenable to oxidative coupling. Moreover, the data of this study show that hydrolytic alteration of the sorbent SOM by microorganisms may be pronounced and would, as a consequence, counteract the intended immobilization.

\section{Conclusions}

The action of hydrolytic exoenzymes, namely of cellulase, facilitates the release of HOC like PAH and PCB from soil and increases contaminant availability. This effect may be due to the loss of polymeric sorbent through its transformation into water soluble DOM or, more likely, to the acceleration in mass transfer as a consequence of decreasing sorbent rigidity by the loss of cross-linkages in SOM.

These results indicate that sorption properties of a soil are biologically influenced. Changes in physical or chemical soil conditions that increase (micro-) biological activity could enhance the release of aged organic contaminants. Also climate change would increase the release of HOC in two ways, directly by shifting the temperature-dependent sorption equilibrium to the dissolved phase as well as indirectly by increasing the biological activity in soils.

In the present study free enzymes have been added to soil in short term batch experiments. Future studies need to show to which extent the variation of the native microbial activity in soils modulates the availability of HOC and whether other hydrolytic enzymes such as proteases show a similar effect. Especially the lysis of lignin constituents could exhibit a strong mobilizing effect, because lignin or lignin derived organic matter is both, a good sorbent for HOC and a major constituent of SOM. Finally, a comparison of the mobilizing effect of these different enzymes may allow to elucidate which domains of SOM are most important for the sorption of HOC in soil.

\section{Acknowledgements}

This work was financially supported by the German Research Council (DFG, Bonn) through "INTERURBAN - TP MOBIL" (RE 1290/5-3, 5-4). We thank Elke Profft for valuable support in the laboratory and the Department of Soil Science of TU Berlin for soil analyses.

\section{References}

Berry, D.F., Boyd, S.A., 1985. Decontamination of soil through enhanced formation of bound residues. Environ. Sci. Technol. 19, 1132-1133.

Bertino, D.J., Albro, P.W., Hass, J.R., 1987. Enzymatic hydrolysis of carbohydrates in aquatic fulvic acids. Environ. Sci. Technol. 21, 859-863.

Bollag, J.M., 1992. Decontaminating soil with enzymes. Environ. Sci. Technol. 26, $1876-1881$.

Burns, R.G., 1977. Soil enzymology. Sci. Prog. 64, 275-285.

Burns, R.G., 1982. Enzyme activity in soil - location and a possible role in microbial ecology. Soil Biol. Biochem. 14, 423-427.

Deng, S.P., Tabatabai, M.A., 1994. Cellulase activity of soils. Soil Biol. Biochem. 26, 1347-1354.

Evans, C.D. Chapman, PJ. Clark, J.M., Monteith, D.T. Cressers, M.S., 2006 Alternative explanation for rising dissolved organic carbon export from organic soils. Global Change Biol. 12, 2044-2053.

Hayes, M.B.H., MacCarthy, P., Malcom, R., Swift, R.S., 1989. Humic Substances II: In Search of Structure. John Wiley and Sons, New York. p. 689.

Hruska, J., Kram, P., McDowell, W.H., Oulehle, F., 2009. Increased dissolved organic carbon $(D O C)$ in Central European streams is driven by reduction in ionic 
CHEM 10654

ARTICLE IN PRESS

No. of Pages 9, Model 5G

18 December 2009

8

D. Wicker, T. Reemtsma/Chemosphere $x x x$ (2009) $x x x-x x x$

558
559
560
561
562
563
564
565
566
567
568
569
570
571
572
573
574
575
576
577
578
579
580
581
582
583
584
585
586
587
588
589
590
591
592
593
594

strength rather than climate change or decreasing acidity. Environ. Sci. Technol. 43, 4320-4326.

Huang, Q.Y., Liang, W., Cai, P., 2005. Adsorption, desorption and activities of acid phosphatase on various colloidal particles from an Ultisol. Colloids Surf. B 45, 209-214.

Jonker, M.T.O., 2008. Absorption of polycyclic aromatic hydrocarbons to cellulose. Chemosphere 70, 778-782.

Karickhoff, S.W., Brown, D.S., Scott, T.A., 1979. Sorption of hydrophobic pollutants on natural sediments. Water Res. 13, 241-248.

Krauss, M., Wilcke, W., 2001. Predicting soil-water partitioning of polycyclic aromatic hydrocarbons and polychlorinated biphenyl by desorption with methanol-water mixtures at different temperatures. Environ. Sci. Technol. 35, 2319-2325.

tad, J.N., Butler, J.H.A., 1971. Inhibition by soil humic acids of native and acetylated proteolytic enzymes. Soil Biol. Biochem. 3, 157-160.

Lahdesmaki, P., Piispanen, R., 1988. Degradation products and the hydrolytic enzyme activities in the soil humification processes. Soil Biol. Biochem. 20, 287-292.

Lahdesmaki, P., Piispanen, R., 1992. Soil enzymology: role of protective colloid systems in the preservation of exoenzyme activities in soil. Soil Biol. Biochem. 24, 1173-1177.

Lang, V., 1992. Polychlorinated-biphenyls in the environment. J. Chromatogr. 595, $1-43$.

Leboeuf, E.J., Weber, J.W., 2000. Macromolecular characteristics of natural organic matter. 2. Sorption and desorption behaviour. Environ. Sci. Technol. 34, 36323640.

Majumdar, S.K., Roo, C.V.N., 1978. Physico-chemical studies on enzyme-degraded fulvic acid. J. Soil Sci. 29, 489-497.

Means, J.C., Wood, S.G., Hassett, J.J., Banwart, W.L., 1980. Sorption of polynuclear aromatic hydrocarbons by sediments and soils. Environ. Sci. Technol. 14, 15241528 .

Moorhead, D.L., Sinsabaugh, R.L., 2000. Simulated patterns of litter decay predict patterns of extracellular enzyme activities. Appl. Soil Ecol. 14, 71-79.

Quiquampoix, H., Staunton, S., Baron, M.H., Ratcliffe, R.G., 1993. Interpretation of the $\mathrm{pH}$ dependence of protein adsorption on clay mineral surfaces and its relevance to the understanding of extracellular enzyme activity in soil. Colloids Surf. A 75, 85-93.
Reemtsma, T., Savric, I., Hartig, C., Jekel, M., 1997. PCB and LAS as indicators of accumulation, biodegradation and transport processes in sewage farm soils. In: Eganhouse, R.B. (Ed.), Molecular Markers in Environmental Geochemistry. Am. Chem. Soc. Sym. Ser., Washington, pp. 213-230 (Chapter 14).

Reemtsma, T., Savric, I., Jekel, M., 2003. A potential link between the turnover of soil organic matter and the release of aged organic contaminants. Environ. Toxicol. Chem. 22, 760-766.

Sarkar, J.M., Leonowicz, A., Bollag, J.M., 1989. Immobilization of enzymes on clays and soils. Soil Biol. Biochem. 21, 223-230.

Schimmel, J.P., Weintraub, M.N., 2003. The implication of exoenzyme activity on microbial carbon and nitrogen limitation in soil: a theoretical model. Soil Biol. Biochem. 35, 549-563.

Schinner, F., van Mersi, W., 1990. Xylanase-activity, Cm-cellulase-activity and invertase activity in soil - an improved method. Soil Biol. Biochem. 22, 511515.

Stemmer, M., Gerzabek, M.H., Kandeler, E., 1999. Invertase and xylanase activity of bulk soil and particle-size fractions during maize straw decomposition. Soil Biol. Biochem. 31, 9-18.

Wang, X.L., Cook, R., Tao, S., King, B., 2007. Sorption of organic contaminants by biopolymers: role of polarity, structure and domain spatial arrangement. Chemosphere 66, 1476-1484.

Weber, W.J., Huang, Q., 2003. Inclusion of persistent organic pollutants in humification processes: direct chemical incorporation of phenanthrene via oxidative coupling. Environ. Sci. Technol. 37, 4221-4227.

Wicker, D., Böckelmann, U., Reemtsma, T., 2007. Experimental and modeling approach to study sorption of dissolved hydrophobic organic contaminants to microbial biofilms. Water Res. 41, 2202-2210.

Wicker, D., Böckelmann, U., Reemtsma, T., 2008. Environmental influences on the partitioning and diffusion of hydrophobic organic contaminants in microbial biofilms. Environ. Sci. Technol. 42, 1990-1996.

Wild, S.R., Jones, K.C., 1995. Polynuclear aromatic hydrocarbons in the United Kingdom environment - a preliminary source inventory and budget. Environ. Pollute. 88, 91-108.

Wood, T.M., Bht, K.M., 1988. Methods for measuring cellulase activities. Methods Enzymol. 160, 87-112.

595

596

597

598

599
600

601

602

603

605

606

607

608

610

611

612

613

615

616

617

618

620

621

622

623

625

626

627

628

629

630

Please cite this article in press as: Wicked, D., Reemtsma, T. Mobilization of hydrophobic contaminants from soils by enzymatic depolymerization of soil

organic matter. Chemosphere (2009), doi:10.1016/j.chemosphere.2009.12.009 